Vítor Monteiro, J. G. Pinto, João L. Afonso

"Experimental Validation of a Three-Port Integrated Topology to Interface Electric Vehicles and Renewables with the Electrical Grid"

IEEE Transactions on Industrial Electronics, 2018.

https://ieeexplore.ieee.org/document/8322186

ISSN: $1551-3203$

DOI 10.1109/TII.2018.2818174

This material is posted here with permission of the IEEE. Such permission of the IEEE does not in any way imply IEEE endorsement of any of Group of Energy and Power Electronics, University of Minho, products or services. Internal or personal use of this material is permitted. However, permission to reprint/republish this material for advertising or promotional purposes or for creating new collective works for resale or redistribution must be obtained from the IEEE by writing to pubs-permissions@ieee.org. By choosing to view this document, you agree to all provisions of the copyright laws protecting it. 


\title{
Experimental Validation of a Three-Port Integrated Topology to Interface Electric Vehicles and Renewables with the Electrical Grid
}

\author{
Vítor Monteiro, Student Member, IEEE, J. G. Pinto, Member, IEEE, João L. Afonso, Member, IEEE
}

\begin{abstract}
This paper presents the analysis and the experimental validation of an off-board three-port integrated topology (TPIT) used to interface electric vehicles (EVs) and renewables from solar photovoltaic (PV) panels with the electrical power grid. The TPIT is composed by three power converters sharing a single common dc-link, and it can operate in four different modes towards the future smart grids: (1) The EV batteries are charged with energy from the electrical power grid through the grid-to-vehicle (G2V) operation mode; (2) The EV batteries deliver part of the stored energy back to the power grid through the vehicle-to-grid (V2G) operation mode; (3) The energy produced by the PV panels is delivered to the electrical grid through the renewable-to-grid (R2G) operation mode; (4) The energy produced by the PV panels is used to charge the EV batteries through the renewable-to-vehicle (R2V) operation mode. In addition to individual action, the reorganization of these modes results in new combined operation modes. The paper presents the proposed power theory to control the TPIT, the current control strategies to manage the currents in ac and dc sides of the TPIT, and the details of the developed TPIT prototype, including the hardware and the digital control system. Experimental results that validate the TPIT operation modes are also presented.
\end{abstract}

Index Terms-Electric Vehicle, Integrated Topology, Power Converters, Renewables, Smart Grid.

\section{INTRODUCTION}

$\mathrm{E}$ LECTRIC mobility represents a significant contribution to increase the sustainability and efficiency in the transport sector [1][2], including the use of electric vehicles (EVs), hybrid EVs, fuel cell vehicles [3], and electric bicycles [4]. Nevertheless, the massive introduction of EVs into the electrical grid should be controlled in order to prevent power quality problems [5][6], to optimize its interaction with other electrical appliances [7], as well as to take advantages of their use in the new paradigms of microgrids [8], smart grids and smart homes [9]. In this context, the optimized EV charging process considering the customer perspective, the power demand, and the revenue of the aggregator is presented in

Copyright (c) 2018 IEEE. Personal use of this material is permitted. However, permission to use this material for any other purposes must be obtained from the IEEE by sending a request to pubs-permissions@ieee.org.

Vítor Monteiro, J. G. Pinto, and João L. Afonso are with Centro Algoritmi, University of Minho, Department of. Industrial Electronics, 4800-058 Guimarães, Portugal; emails: vmonteiro@dei.uminho.pt, gpinto@dei.uminho.pt and jla@dei.uminho.pt. (corresponding author phone: +351253510392; e-mail: vmonteiro@dei.uminho.pt).
[10].

Besides the controlled charging process, the introduction of $\mathrm{EVs}$ into the electrical power grid to exchange energy in bidirectional mode through the grid-to-vehicle $(\mathrm{G} 2 \mathrm{~V})$ and vehicle-to-grid (V2G) operation modes is presented in [11]. In this context, a single-phase on-board bidirectional charger with capability to operate in $\mathrm{G} 2 \mathrm{~V}$ and $\mathrm{V} 2 \mathrm{G}$ modes is proposed in [12]. A balancing power demand using the EV in V2G operation for demand response management in smart grids is proposed in [13], a hierarchical energy management strategy to introduce EVs in smart grids is analyzed in [14], the benefits of the $\mathrm{V} 2 \mathrm{G}$ operation mode for balancing power demand in smart grid context is analyzed in [15], and the impact and challenges of $\mathrm{V} 2 \mathrm{G}$ on the electrical grid is presented in [16]. Besides the G2V and V2G operation modes, with the $\mathrm{EV}$ introduction into the electrical grid, new opportunities and challenges emerge for future smart grids in terms of new operation modes [17][18]. In addition, with the progresses in microgeneration, new opportunities also emerge for the integration of EVs with renewables considering different electrical grid constraints [19]. In this context, the contribution of EVs to stabilize the electrical grid voltage considering the introduction of renewables is presented in [20], an energy management strategy considering the EVs operation and the energy production from renewables is presented in [21], an economic dispatch model of EVs with renewables is presented in [22], smart charging strategies for the EV maximizing the use of energy from variable renewable resources are proposed in [23], the impact of EVs and photovoltaic (PV) on future generation in terms of investment is presented in [24], and a cost minimization of charging stations with EVs and PVs is presented in [25]. Besides the EV operation considering renewable energy sources, the incorporation of energy storage systems is also relevant for the energy management in smart grids. A demand-side management controlling EVs (operating as G2V or as V2G), renewable energy sources and energy storage systems is proposed in [26], and a hybrid optimization strategy for economic deployment considering EV charging stations with PVs and energy storage systems is proposed in [27]. These strategies are based on control algorithms to integrate EVs and renewables in electrical grids, e.g., maximizing the energy provided by the PVs, maximizing the cost benefits to the energy dealership, energy balance strategies, the EV charging time and state-of-charge, or the schedule to start and stop the 
EV battery charging process according to the energy provided by renewables. In addition, these strategies focus on the large-scale utilization, with several EVs and renewables distributed in the electrical power grid. Typically, the integration of EVs and renewables with the electrical grid is performed considering different equipment, i.e., two power converters to interface an EV with the electrical grid (an ac-dc and a dc-dc converter) and also two power converters to interface a renewable source with the electrical grid (an ac-dc and a dc-dc converter). The main disadvantage of such traditional topology is associated with the direct EV battery charging process from renewable sources, where it is necessary to use four converters and the electrical grid as intermediary ( $\mathrm{dc}$ to ac stage followed by an ac to dc stage). In order to sidestep this drawback, this paper presents the experimental validation of a single-phase off-board three-port integrated topology (TPIT) for residential purpose, aiming to interface EVs and renewables with the electrical grid through an ac-dc converter and two dc-dc converters. Fig. 1 presents the interface between an EV and PV panels with the electrical grid using the classical topology (cf. Fig. 1(a)) and the proposed topology (cf. Fig. 1(b)).

A multi-objective optimal scheduling for the introduction of EVs charging stations, PV panels and storage batteries in a dc micro-grid scenario connected to a three-phase power grid is presented in [28]. A system to interface EVs (using an external dc-dc charger) and PV panels (using a traditional inverter) with the electrical power grid is presented in [29], however, the hardware topology is not discussed neither the control algorithm and the power quality issues. A novel system based on a multimode single-leg power converter is proposed in [30] to control the power flow between dc systems, including renewables and an energy storage system, but without the power grid interface. A multi-port topology to deal with an EV, PV panels and the power grid is presented in [31], however, such topology requires the use of two power converters to make the interface with the power grid, one operating as an active rectifier and the other as a grid-tie inverter, representing a great disadvantage in comparison with the topology presented in this paper (which requires a single converter to make the interface with the electrical grid). Topologies that are similar to the one proposed in this paper, also using three power converters, are presented in [32] and [33], however, the main advantage of the proposed topology in contrast with such references, is the possibility of having the EV operating in bidirectional mode, i.e., charging the batteries from the electrical grid or from the PV panels, or delivering energy to the electrical grid. Moreover, the power quality issues (total harmonic distortion of the grid current and power factor) in the electrical grid side are not considered in any of these works, representing a disadvantage, but highlights the relevance of the experimental study proposed in this paper. A comparative analysis between the classical and the proposed topology in terms of estimated operation efficiency and cost of implementation is presented in [34]. The proposed topology presents a maximum estimated efficiency $8.8 \%$ higher, and a total cost $33.5 \%$ lower, comparing with the classical solution

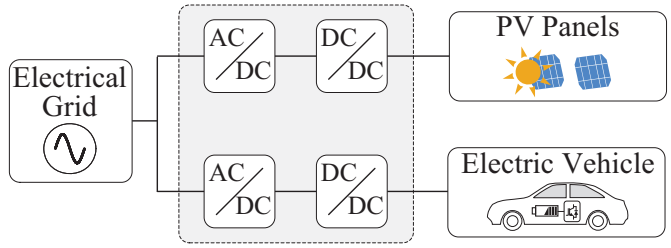

(a)

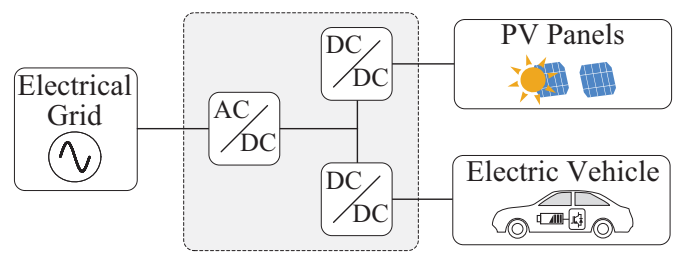

(b)

Fig. 1. Interface between an EV and PV panels with the electrical grid: (a) Classical topology; (b) Proposed topology.

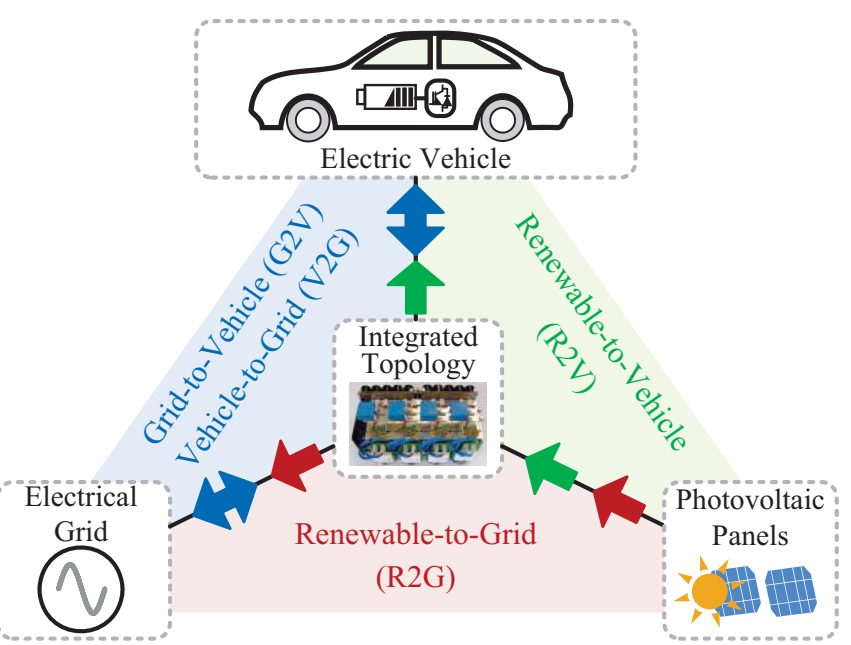

Fig. 2. Proposed three-port integrated topology (TPIT) used to interface electric vehicles (EVs) and renewables from photovoltaics (PV) with the electrical grid through the $\mathrm{G} 2 \mathrm{~V}, \mathrm{~V} 2 \mathrm{G}, \mathrm{R} 2 \mathrm{~V}$ and $\mathrm{R} 2 \mathrm{G}$ operation modes.

(cf. Fig. 1(a)).

Fig. 2 shows the interconnection between the TPIT, the EV, the PV panels, and the electrical grid. This interconnection can be performed through four different modes towards the future smart grids: (1) Grid-to-vehicle (G2V) operation mode, where the EV batteries are charged from the electrical grid; (2) Vehicle-to-grid (V2G) operation mode, where part of the energy stored in the EV batteries is delivered back to the electrical grid; (3) Renewable-to-grid (R2G) operation mode, where the energy produced by the PV panels is delivered to the electrical grid and the EV is not in charging; (4) Renewable-to-vehicle (R2V) operation mode, where the energy produced by the PV panels is used to charge the EV batteries. Besides individual action, these modes can be reorganized for combined operation modes. The proposed TPIT is focused for residential level with a single EV and a set of PV panels aiming to reduce carbon footprint, improve the self-energy consumption and the energy efficiency. Comparing with the state-of-the-art topologies, the main contributions of the proposed topology are: Single ac-dc converter to interface an EV battery charger and renewables 


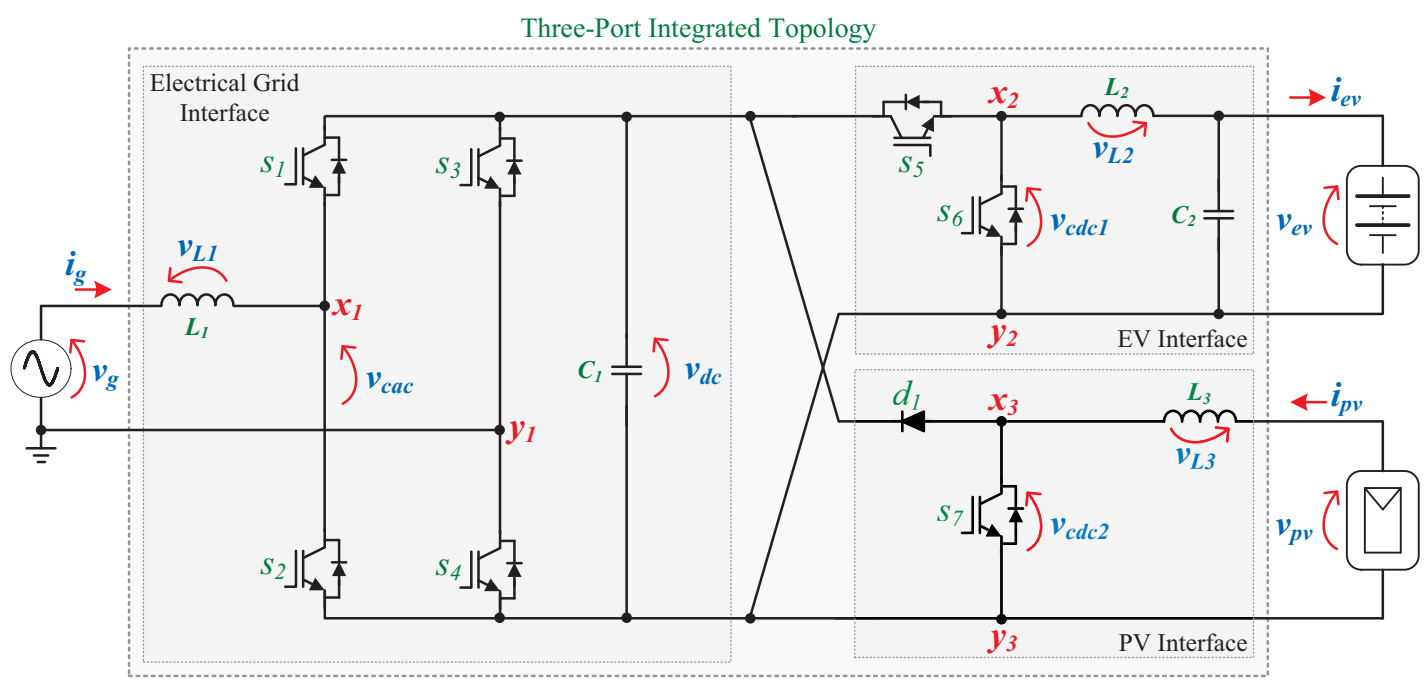

Fig. 3. Circuit of the proposed three-port integrated topology (TPIT) used to interface EVs and renewables with the electrical grid.

with the electrical grid; Possibility to perform the EV battery charging process directly from the PV panels without the electrical grid as energy intermediary or during power outages of the power grid (direct dc to dc interface proposed as R2V operation mode); Single dc-link to interface the ac-dc converter and the two dc-dc converters; Sinusoidal grid current and unitary power factor in all operating modes to prevent power quality problems; Experimental validation at residential level with the TPIT operating during the G2V, V2G, R2G and R2V operation modes. In the scope of this paper only PVs were considered, since they are the more common renewable energy source used at residential level. However, other types of renewables could be applied, such as micro-wind energy, using other power converter and control algorithm.

The rest of the paper is organized as follows: The digital control algorithm is presented in section II, while the principle of operation is presented in section III. The experimental validation in four distinct operation modes is presented in section IV and the main conclusions in section V.

\section{Three-Port InTEgRATED TOPOlOgY: Digital Control Algorithm}

The circuit schematic of the TPIT is presented Fig. 3, where is presented the ac-dc bidirectional full-bridge converter used to interface the power grid, the dc-dc bidirectional half-bridge converter used to interface the EV batteries, and the dc-dc unidirectional half-bridge converter used to interface the PV panels. In addition to the previously highlighted advantages (cf. section I), this topology was selected due to the possibility to integrate the three converters in a single dc-link, maintaining the characteristics of each converter. The EV is not galvanic isolated from the PV or from the power grid, since the galvanic isolation only must be guaranteed between the traction batteries and the vehicle chassis according to the IEC 61851-1 standard. The operation of the TPIT is defined according to the EV operation mode $(\mathrm{G} 2 \mathrm{~V}$ or $\mathrm{V} 2 \mathrm{G})$ and the available energy from the PV panels (R2G or R2V).
Therefore, a power theory should be defined in order to establish the current references for the TPIT operation according to the different operation modes. Thus, the grid power $\left(p_{g}\right)$ is defined according to:

$$
p_{g}=p_{d c}+p_{p v}+p_{e v}
$$

where, $p_{p v}$ denotes the PV panels power, $p_{e v}$ means the EV power (which is positive during the G2V mode and negative during the $\mathrm{V} 2 \mathrm{G}$ mode), and $p_{d c}$ represents the power necessary to regulate the dc-link voltage through a proportional-integral controller according to:

$$
p_{d c}=k_{p}\left(v_{d c}{ }^{*}-v_{d c}\right)+k_{i} \int\left(v_{d c}{ }^{*}-v_{d c}\right),
$$

where, $v_{d c} *$ denotes the dc-link voltage reference and $v_{d c}$ the measured dc-link voltage shared by all the converters. From equation (1), the rms value of the grid current can be defined by:

$$
I_{G}=\frac{p_{d c}+v_{p v} i_{p v}+v_{e v} i_{e v}}{V_{G}}
$$

where, $v_{p v}$ and $i_{p v}$ are the voltage and the current in the PV panels, and $v_{e v}$ and $i_{e v}$ are the voltage and the current in the EV batteries. Taking into account that the TPIT operates with sinusoidal grid current, the grid current reference $\left(i_{g}{ }^{*}\right)$ is determined using a power theory, i.e., it is obtained a signal directly proportional to the electrical grid voltage $\left(v_{g}\right)$ [35]. In the scope of this paper, the power theory is based on the Fryze-Buchholz-Depenbrock (FBD) method [36], where a converter can be seen as a conductance $\left(G_{G}\right)$. From the electrical grid point of view, the TPIT can operate as a linear load (consuming sinusoidal current in phase with the voltage, i.e., as an active rectifier) or as a current source (injecting sinusoidal current into the electrical grid in phase opposition with the voltage, i.e., as a grid-tie inverter). Therefore, the rms value of the current in the electrical grid side can be established by:

$$
I_{G}=G_{G} V_{G},
$$

and its instantaneous value by:

$$
i_{g}=G_{G} v_{g}
$$

Substituting the equation (4) in the equation (5), the instantaneous grid current is established by: 


$$
i_{g}=\frac{I_{G}}{V_{G}} v_{g} .
$$

Substituting the equation (3) in the equation (6), the final equation that defines the instantaneous grid current $\left(i_{g}\right)$ in function of the EV and PV operation is defined by:

$$
i_{g}=\frac{p_{d c}+v_{p v} i_{p v}+v_{e v} i_{e v}}{V_{G}^{2}} v_{g} .
$$

According to equations (7) and (1), it is possible to verify the contribution of the EV operating power $\left(p_{e v}\right.$ - positive during the G2V mode and negative during the V2G mode) and the PV operating power $\left(p_{p v}\right)$ to define the instantaneous value of the grid current $\left(i_{g}\right)$. The value of $p_{d c}$ is always positive and the values assumed by $v_{p v} i_{p v}$ and $v_{e v} i_{e v}$ define if the grid current is in phase or phase opposition with the electrical grid voltage. It is important to note that the PV current $\left(i_{p v}\right)$ is controlled accordingly to its reference established by a specific algorithm (cf. section II.C), and the EV current $\left(i_{e v}\right)$ is controlled accordingly to its reference established by the battery management system (BMS) (cf. section II.B). Since the instantaneous values of all the ac and dc variables are acquired by the digital control system (with a sampling frequency of $40 \mathrm{kHz}$ ), the operating power in each port is automatically calculated by the control system with the same sampling rate.

Analyzing equation (7), it is possible to verify that the grid current $\left(i_{g}\right)$ is also directly influenced by the grid voltage $\left(v_{g}\right)$, meaning that the harmonic distortion presented in the grid voltage will be reflected in the grid current. Directly using the measured grid voltage represents a disadvantage, since the TPIT would contribute to aggravate the problem of harmonic currents in the electrical grid. To avoid this drawback, instead of using the measured voltage it is used a signal proportional to its fundamental component, i.e., a sinewave signal with the fundamental frequency of the electrical grid $(50 \mathrm{~Hz}-$ in Europe). This signal is obtained from a phase-locked loop (PLL) algorithm [37].

For the ac-dc converter, analyzing the voltages between the electrical grid and the TPIT, it can be established:

$$
v_{c a c}=v_{g}-L_{1} \frac{d i_{g}}{d t},
$$

where, the instantaneous value of the voltage established by the TPIT in the ac side $\left(v_{c a c}\right)$ is defined in accordance with the electrical grid voltage and the voltage across $L_{1}$. Applying the forward Euler method, the digital implementation results in:

$$
v_{c a c}[k]=v_{g}[k]-\frac{L_{1}}{T}\left(i_{g}{ }^{*}[k]-i_{g}[k]\right),
$$

where, $i_{g} *$ means the grid current reference and $k$ the actual sample (determined by the timer interruption) in the digital control system. The gate pulse patterns for the ac-dc converter are obtained comparing the voltage reference $\left(v_{c a c}\right)$ with a $20 \mathrm{kHz}$ triangular carrier using a unipolar PWM strategy in order to obtain a current ripple with lower amplitude and with the double of the switching frequency $(40 \mathrm{kHz})$. For the dc-dc converter used to interface the PV panels, analyzing the voltages it can be established:

$$
v_{c d c 2}=v_{p v}-L_{3} \frac{d i_{p v}}{d t}
$$

where, applying the forward Euler method, the digital implementation results in:

$$
v_{c d c 2}[k]=v_{p v}[k]-\frac{L_{3}}{T}\left(i_{p v}{ }^{*}[k]-i_{p v}[k]\right) .
$$

where, $i_{p v} *$ denotes the current reference and is established by the maximum power point tracking (MPPT) algorithm (cf. section IV). For the dc-dc converter used to interface the EV batteries, analyzing the voltages it can be established:

$$
v_{c d c 1}=v_{e v}+L_{2} \frac{d i_{e v}}{d t},
$$

where, applying the forward Euler method, the digital implementation results in:

$$
v_{c d c 1}[k]=v_{e v}[k]+\frac{L_{2}}{T}\left(i_{e v}{ }^{*}[k]-i_{e v}[k]\right) .
$$

where, $i_{e v} *$ denotes the current reference for charging the batteries and is established by the BMS. The gate pulse patterns for the dc-dc converters are obtained comparing the voltages references $\left(v_{c d c 1}\right.$ and $\left.v_{c d c 2}\right)$ with two $20 \mathrm{kHz}$ triangular carriers. When the EV batteries are charged only from the PV panels, the current reference $i_{e v} *$ is determined in function of the EV batteries voltage and the power in the PV panels.

\section{A. Ac-Dc Bidirectional Converter}

The ac-dc bidirectional converter is used as interface between the electrical grid and the dc-link, and it is controlled in order to obtain a sinusoidal grid current (in phase or phase opposition with the electrical grid voltage, according to the operation mode) and to maintain the dc-link voltage controlled. The voltage produced by this converter (cf. $v_{c a c}$ ) can assume three distinct values according to the state of the IGBTs. The voltage $v_{c a c}$ is 0 when the IGBTs $S_{2}$ and $S_{4}$ are on (or when $S_{1}$ and $S_{3}$ are on), and the IGBTs $S_{1}$ and $S_{3}$ are off (or when $S_{2}$ and $S_{4}$ are off). The voltage $v_{c a c}$ is $+v_{d c}$ when the IGBTs $S_{1}$ and $S_{4}$ are on, and the IGBTs $S_{2}$ and $S_{3}$ are off. The voltage $v_{c a c}$ is $-v_{d c}$ when the IGBTs $S_{1}$ and $S_{4}$ are off, and the IGBTs $S_{2}$ and $S_{3}$ are on.

\section{B. Dc-Dc Bidirectional Converter}

The dc-dc bidirectional converter is used as interface between the dc-link and the EV batteries and is controlled to charge the batteries with constant current or to discharge the batteries with controlled current according to the requirements of the electrical grid, during the V2G operation mode. This converter operates in the continuous mode, and the voltage produced (cf. $v_{c d c l}$ ) can assume two distinct values according to the state of the IGBTs. During the EV battery charging process ( $\mathrm{G} 2 \mathrm{~V}$ operation mode): When the IGBT $S_{5}$ and the IGBT $S_{6}$ are off the voltage $v_{c d c l}$ is 0 ; When the IGBT $S_{5}$ is on and the IGBT $S_{6}$ is off the voltage $v_{c a c l}$ is $+v_{d c}$. On the other hand, during the EV battery discharging process (V2G operation mode): When the IGBT $S_{5}$ and the IGBT $S_{6}$ are off the voltage $v_{c d c l}$ is $+v_{d c}$; When the IGBT $S_{5}$ is off and the IGBT $S_{6}$ is on the voltage $v_{c d c l}$ is 0 .

\section{Dc-Dc Unidirectional Converter}

The dc-dc unidirectional converter is used as interface between the dc-link and the PV panels and is controlled in order to extract the maximum power from the PV panels 


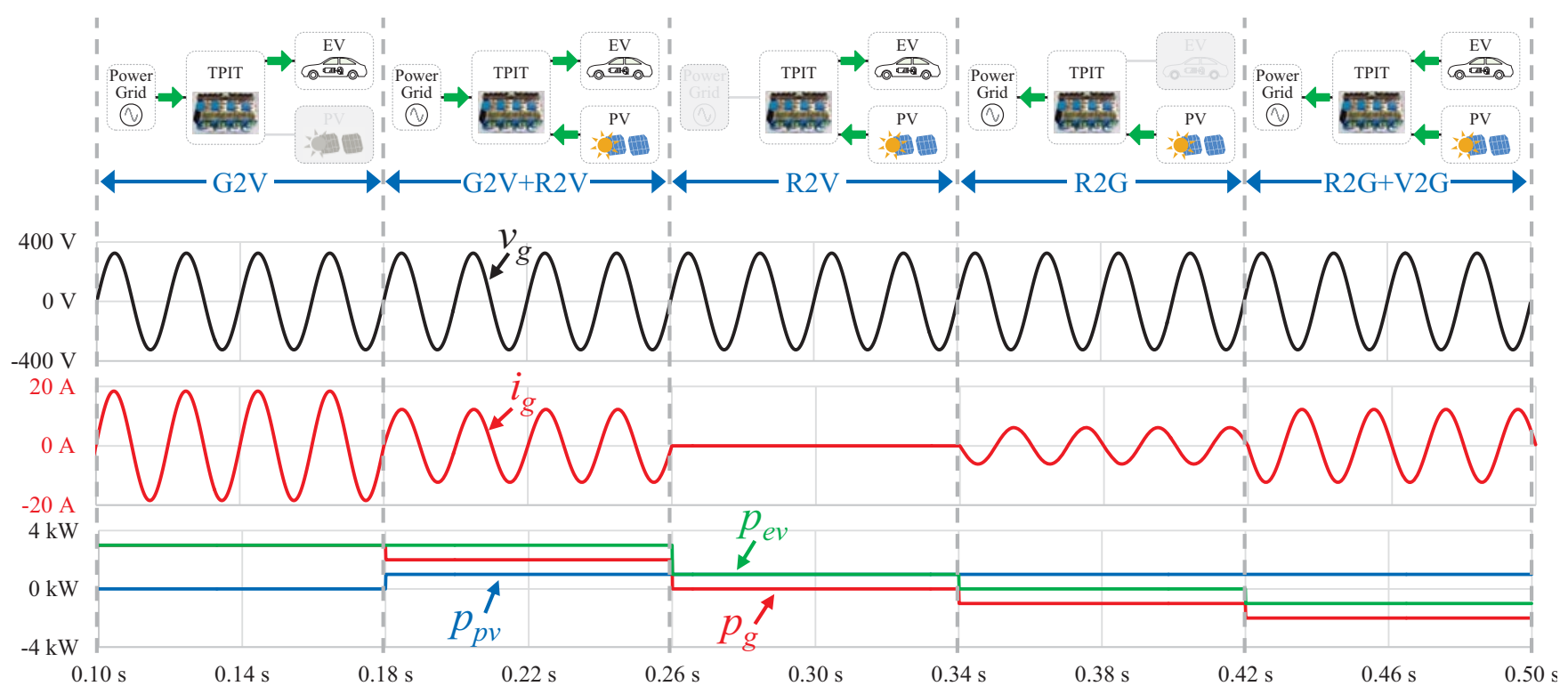

Fig. 4. Principle of operation of the proposed three-port integrated topology (TPIT) used to interface EVs and renewables with the electrical grid: Grid voltage $\left(v_{g}\right)$; Grid Current $\left(i_{g}\right)$; Grid power $\left(p_{g}\right)$; EV power $\left(p_{e v}\right)$; PV power $\left(p_{p v}\right)$.

through a MPPT algorithm. This converter operates in the continuous mode and the voltage produced (cf. $v_{c d c 2}$ ) can assume two distinct values according to the state of the IGBT. When the IGBT $S_{7}$ is off the voltage $v_{c d c 2}$ is $+v_{d c}$. When the IGBT $S_{7}$ is on the voltage $v_{c d c 2}$ is 0 .

\section{THREE-Port INTEGRATED TOPOLOGY: PRINCIPLE OF OPERATION}

Fig. 4 shows a typical operation of the TPIT considering the $\mathrm{G} 2 \mathrm{~V}, \mathrm{~V} 2 \mathrm{G}, \mathrm{R} 2 \mathrm{~V}$ and R2G modes, where, $v_{g}$ denotes the electrical grid voltage, $i_{g}$ means the current in the electrical grid, and $p_{g}, p_{e v}, p_{p v}$ are, respectively, the grid power, the EV power and the PV power. These results were obtained with computer simulations using the software PSIM v9.0. During the first time interval (from $0.1 \mathrm{~s}$ to $0.18 \mathrm{~s}$ ) the TPIT is controlled to operate in $\mathrm{G} 2 \mathrm{~V}$ operation mode, i.e., the $\mathrm{EV}$ batteries are charged with energy provided only by the electrical grid. Therefore, the value of the grid power $\left(p_{g}\right)$ is equal to the value of the EV power $\left(p_{e v}\right)$. During the second time interval (from $0.18 \mathrm{~s}$ to $0.26 \mathrm{~s}$ ), the TPIT is controlled to charge the EV batteries (G2V operation mode) and to extract the maximum power from the PV panels (R2V operation mode), i.e., the EV batteries are charged with energy provided by the electrical grid and by the PV panels. Therefore, the value of the grid power $\left(p_{g}\right)$ is the difference between the EV power $\left(p_{e v}\right)$ and the PV power $\left(p_{p v}\right)$. During the third time interval (from $0.26 \mathrm{~s}$ to $0.34 \mathrm{~s}$ ), the TPIT is controlled to charge the EV batteries (G2V operation mode) and to extract the maximum power from the PV panels (R2V operation mode), where, the EV batteries are charged with energy provided only by the PV panels. Therefore, the value of the PV power $\left(p_{p v}\right)$ is equal to the EV power $\left(p_{e v}\right)$. During the fourth time interval (from $0.34 \mathrm{~s}$ to $0.42 \mathrm{~s}$ ), the TPIT is controlled to extract the maximum power from the PV panels (R2G operation mode) and to inject it into the electrical grid. Therefore, the value of the PV power $\left(p_{p v}\right)$ is equal to the grid power $\left(p_{g}\right)$. The negative value of $p_{g}$ means that the electrical grid receives energy. It is important to note that the R2V and R2G operation modes can occur simultaneously, i.e., the power from the PV panels is used to charge the EV (R2V operation mode) and the surplus is injected into the electrical grid (R2G operation mode). This case is not shown in the figure due to space restrictions. During the fifth time interval (from $0.42 \mathrm{~s}$ to $0.5 \mathrm{~s}$ ), the TPIT is controlled to extract the maximum power from the PV panels (R2G operation mode) and to deliver back to the electrical grid part of the energy stored in the EV batteries (V2G operation mode). Therefore, the value of the grid power $\left(p_{g}\right)$ is the sum of the EV power $\left(p_{e v}\right)$ and the PV power $\left(p_{p v}\right)$.

\section{EXPERIMENTAL VALIDATION}

Fig. 5 shows the flowchart of the control algorithm. When a timer interrupt occurs (at each $25 \mu \mathrm{s}$ ) the first task is to acquire the voltages and currents through an external ADC. After that, it is defined the operation mode according to the energy produced from the PV and the EV operation. The control algorithm used to extract the maximum power from the PV panels is based on the MPPT perturb and observe algorithm [38]. In the scope of this paper, a set of lead-acid batteries with nominal voltage of $288 \mathrm{~V}$ were used (which constitute the battery pack of an EV [39]), as well as a circuit composed by an adjustable dc source with a series resistor to emulate the PV panels.

The PV current reference $\left(i_{p v} *\right)$ for the instant $k$ is established from the power available in the PV panels $\left(p_{p v}\right)$ also in the instant $k$. On the other hand, the EV operation in $\mathrm{G} 2 \mathrm{~V}$ or $\mathrm{V} 2 \mathrm{G}$ modes is defined by the EV user according to their benefits and the status of the battery state-of-charge estimated by the BMS. According to the power available in PV panels (current reference obtained from the MPPT algorithm) and the EV operation mode (current reference to charge or discharge the batteries obtained from the BMS) is 


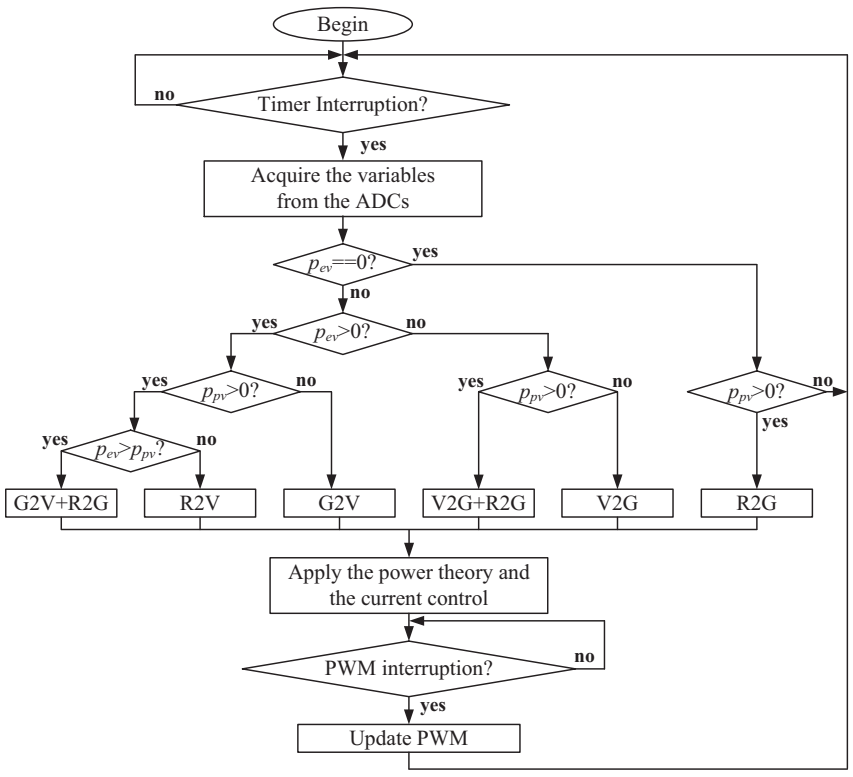

Fig. 5. Flowchart of the proposed TPIT control algorithm.

calculated the grid current reference $\left(i_{g}{ }^{*}\right)$ and are applied predictive current control strategies for the ac-dc converter and for both dc-dc converters. As aforementioned, it is important to note that the grid current reference $\left(i_{g}{ }^{*}\right)$ is calculated using the output signal of a PLL algorithm in order to be sinusoidal. When a PWM interrupt occurs, the PWM comparison registers are updated in order to control the respective currents.

Fig. 6 shows the developed prototype of the TPIT that was specifically developed in order to validate the hardware topology, the control algorithms and to obtain the experimental results. As shown, the TIPT was assembled in an electrical switchboard to be used in an off-board application. This prototype is divided in two main parts: the power converters and the digital control system. The TPIT is composed by four IGBTs modules SKM50GB12V from Semikron (two for the ac-dc converter and two for the dc-dc converters) mounted in the same heatsink, and by the passive filters (dc-link capacitors, and inductances for the ac and dc sides). The digital control system is composed by the digital signal processor (DSP) TMS320F28335 from Texas Instruments, by the signal conditioning circuit used to adapt the measured signals from the voltage and current sensors to the input of the ADC MAX1320 from Maxim, by the command circuit used to interface the DSP and the IGBTs drivers, and by the IGBTs drivers SKHI 22A R from Semikron. The specifications and the key components of the TPIT are presented in Table I. The values of the key components were dimensioned according to the detailed explanation presented in [40]. Considering that the focus of this paper is in the integrated topology, a passive L filter was used to interface the power grid once it is the simplest filter and the easier to control when is required to control the grid current during the operation as active rectifier or grid-tie inverter [41].

The experimental results were obtained with a Yokogawa DL708E digital oscilloscope in four specific operation modes:

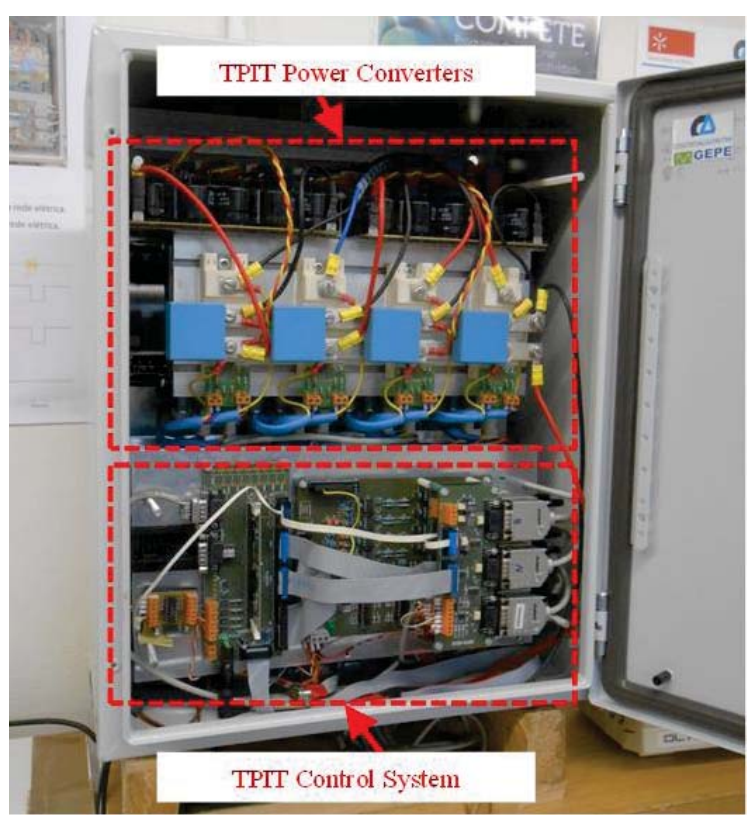

Fig. 6. Developed prototype of the proposed TPIT.

TABLE I

SPECIFICATIONS AND KEY COMPONENTS

\begin{tabular}{ccc}
\hline \hline Parameters & Value & Unit \\
\hline Nominal Grid Voltage & 230 & $\mathrm{~V}$ \\
Nominal Grid Current & 16 & $\mathrm{~A}$ \\
Nominal Power & 3.5 & $\mathrm{~kW}$ \\
Electrical Grid Frequency & 50 & $\mathrm{~Hz}$ \\
Sampling Frequency & 40 & $\mathrm{kHz}$ \\
Switching Frequency & 20 & $\mathrm{kHz}$ \\
Current THD @ Full Power & $<1.5 \%$ & - \\
TPF @ Full Power & 1 & - \\
Nominal dc-link Voltage & 400 & $\mathrm{~V}$ \\
Batteries Voltage & 200 to 400 & $\mathrm{~V}$ \\
Nominal Batteries Current & 10 & $\mathrm{~A}$ \\
Nominal PV Voltage & 200 & $\mathrm{~V}$ \\
Nominal PV Current & 6 & $\mathrm{~A}$ \\
Input Inductance $\left(L_{1}\right)$ & 5 & $\mathrm{mH}$ \\
Dc-link Capacitor $\left(C_{l}\right)$ & 5 & $\mathrm{mF}$ \\
Output Inductance $\left(L_{2}\right)$ & 3 & $\mathrm{mH}$ \\
Output Inductance $\left(L_{3}\right)$ & 3 & $\mathrm{mH}$ \\
Output Capacitor $\left(C_{2}\right)$ & 0.5 & $\mathrm{mF}$ \\
\hline \hline
\end{tabular}

(1) The EV operating through the G2V and then through the V2G mode; (2) The electrical grid receiving energy from the PV panels through the R2G mode; (3) The EV receiving energy from the PV panels through the R2V mode; (4) The EV receiving energy from the electrical grid and from the PV panels, the electrical grid receiving energy from the PV panels, and the electrical grid receiving energy from the EV and from the PV panels.

\section{A. G2V and V2G Operation Modes}

Fig. 7 shows the electrical grid voltage $\left(v_{g}\right)$ and the grid current $\left(i_{g}\right)$ during the G2V operation mode for an operating power of $3 \mathrm{~kW}$. Due to the proposed control algorithm (cf. section II), during this operation mode the grid current $\left(i_{g}\right)$ is sinusoidal, even with a distorted electrical grid voltage (the 


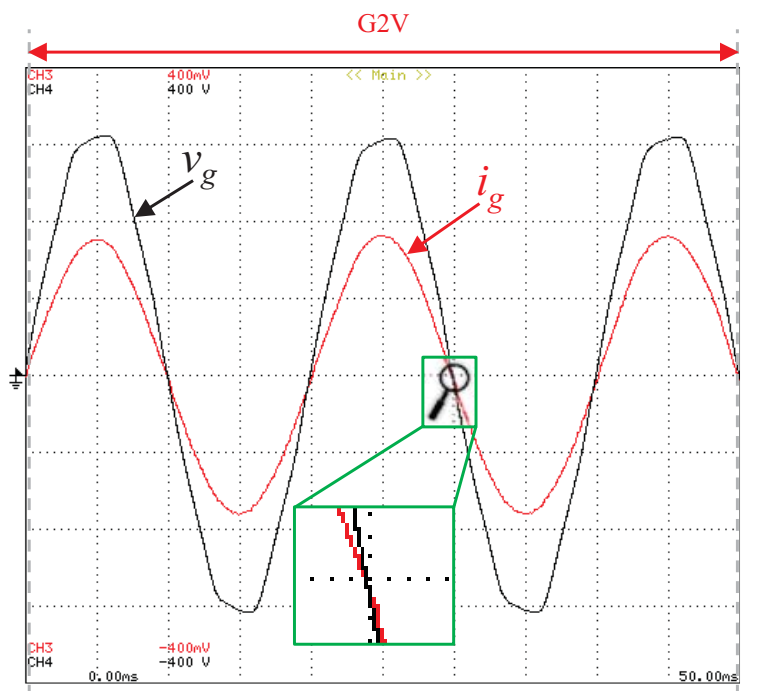

Fig. 7. Experimental results during the G2V operation mode: Grid voltage ( $v_{g}$ : $100 \mathrm{~V} /$ div $)$ and grid current $\left(i_{g}: 10 \mathrm{~A} / \mathrm{div}\right)$.

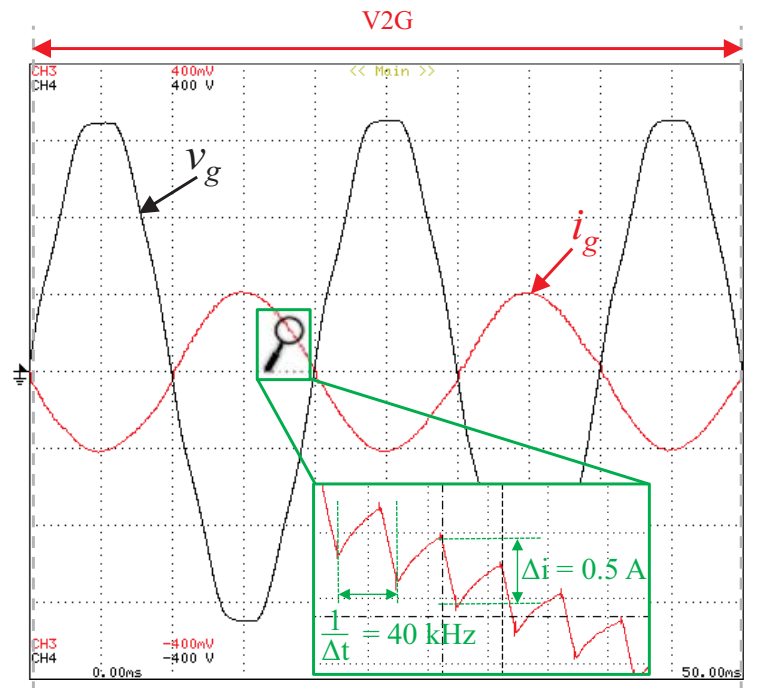

Fig. 8. Experimental results during the V2G operation mode: Grid voltage $\left(v_{g}\right.$ : $100 \mathrm{~V} /$ div) and grid current $\left(i_{g}: 10 \mathrm{~A} /\right.$ div $)$.

THD of the grid voltage is $3.5 \%$ due to the line impedance and the nonlinear loads connected in the same electrical installation), and in phase with the electrical grid voltage $\left(v_{g}\right)$ fundamental component. An explanation about the importance of having a sinusoidal grid current regardless the electrical grid voltage harmonic distortion is presented in section II. In Fig. 7, it is also possible to see in detail when the grid current $\left(i_{g}\right)$ and the electrical grid voltage $\left(v_{g}\right)$ cross zero value, demonstrating that the TPIT operates with unitary power factor during this mode.

On the other hand, Fig. 8 shows the electrical grid voltage $\left(v_{g}\right)$ and the grid current $\left(i_{g}\right)$ during the V2G operation mode for an operating power of $1.6 \mathrm{~kW}$. Also in this operation mode, due to the proposed control algorithm, the grid current $\left(i_{g}\right)$ is sinusoidal regardless the electrical grid voltage harmonic distortion, however, it is in phase opposition with the electrical grid voltage $\left(v_{g}\right)$, meaning that the TPIT is injecting energy into the power grid (i.e., it is operating as a grid-tie inverter). Fig. 8 also shows a detail of the grid current ripple illustrating the frequency of $40 \mathrm{kHz}$ (resultant from the unipolar PWM strategy with a $20 \mathrm{kHz}$ carrier) and the amplitude of the grid current ripple $(0.5 \mathrm{~A})$ in this point of the waveform.

Fig. 9(a) shows the measured THD of the grid current for different power levels of operation (from $500 \mathrm{~W}$ to $3000 \mathrm{~W}$ ) during the $\mathrm{G} 2 \mathrm{~V}$ operation mode. In this case, the minimum measured THD was $1.4 \%$ at $3 \mathrm{~kW}$ and the maximum measured THD was $4.5 \%$ at $500 \mathrm{~W}$. On the other hand, Fig. 9(b) shows the measured THD of the grid current for different power levels of operation (from $500 \mathrm{~W}$ to $2000 \mathrm{~W}$ ) during the $\mathrm{V} 2 \mathrm{G}$ operation mode. In this case, the minimum measured THD was $2.3 \%$ at $2 \mathrm{~kW}$, and the maximum measured THD was $4.8 \%$ at $500 \mathrm{~W}$. These measurements were obtained with the power quality analyzer FLUKE 435. As it can be observed, in both operation modes, the measured values of THD decreases as the operating power increases, validating the proper operation of the current control strategy.

During the EV battery charging process, Fig. 10 shows in detail the current in the inductance $L_{2}\left(i_{L 2}\right)$ and the voltage produced by the converter $\left(v_{d c 2}\right)$ for an operating power of $3 \mathrm{~kW}$. This result was obtained during the EV batteries charging process with constant current. As it can be seen, the switching frequency is $20 \mathrm{kHz}$ and the voltage produced by the converter varies between 0 and $v_{d c}$. The measured current ripple in the inductance $L_{2}\left(i_{L 2}\right)$ is $1.25 \mathrm{~A}$ for a charging current $\left(i_{e v}\right)$ of $10 \mathrm{~A}$.

Fig. 11 shows the grid power $\left(p_{g}\right)$, the EV power $\left(p_{e v}\right)$ and the PV power $\left(p_{p v}\right)$ during the G2V and V2G operation modes. In the scope of this paper, the selection of the operation mode was performed in order to show, firstly the G2V operation mode, and secondly, after a time-delay of $10 \mathrm{~ms}$, the V2G operation mode. However, in a smart grid scenario, the time in each operation mode will be defined according to a request provided by an aggregator (e.g., for contributing to stabilize the amplitude and frequency of the grid voltage) and considering the EV driver benefits. In both operation modes, the grid power is equal to the EV power, meaning that the PV power is zero. In the first time interval (1) the EV power increases progressively, in order to avoid sudden variations, until the power of $3 \mathrm{~kW}$. During the second time interval (2) this power is maintained constant, which corresponds to the normal G2V operation mode, i.e., the EV batteries are charged with constant current. In the third time interval (3) the EV charging process is interrupted, and in the fourth time interval (4) the EV power decreases progressively, in order to avoid sudden variations, until the power of $-2 \mathrm{~kW}$. During the fifth time interval (5) this power is maintained constant, corresponding to the normal $\mathrm{V} 2 \mathrm{G}$ operation mode. The negative value of the power only means that the EV batteries are discharged and the electrical grid receives energy. After this time interval, the $\mathrm{V} 2 \mathrm{G}$ operation mode is interrupted.

\section{B. R2G Operation Mode}

Fig. 12 shows the grid power $\left(p_{g}\right)$, the EV power $\left(p_{e v}\right)$, and the PV power $\left(p_{p v}\right)$ during the R2G operation mode. In this operation mode the EV power is zero and the grid power is equal to the PV power, i.e., all of the energy produced by the PV panels is injected into the electrical grid. Therefore, the 


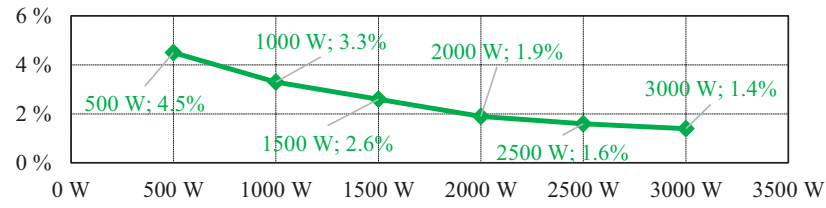

(a)

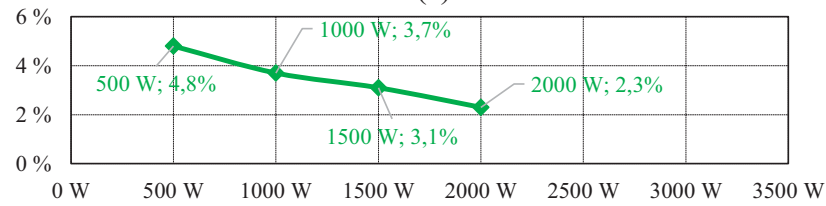

(b)

Fig. 9. Experimental results of the grid current THD in function of the operation power: (a) During the G2V operation mode; (b) During the V2G operation mode.

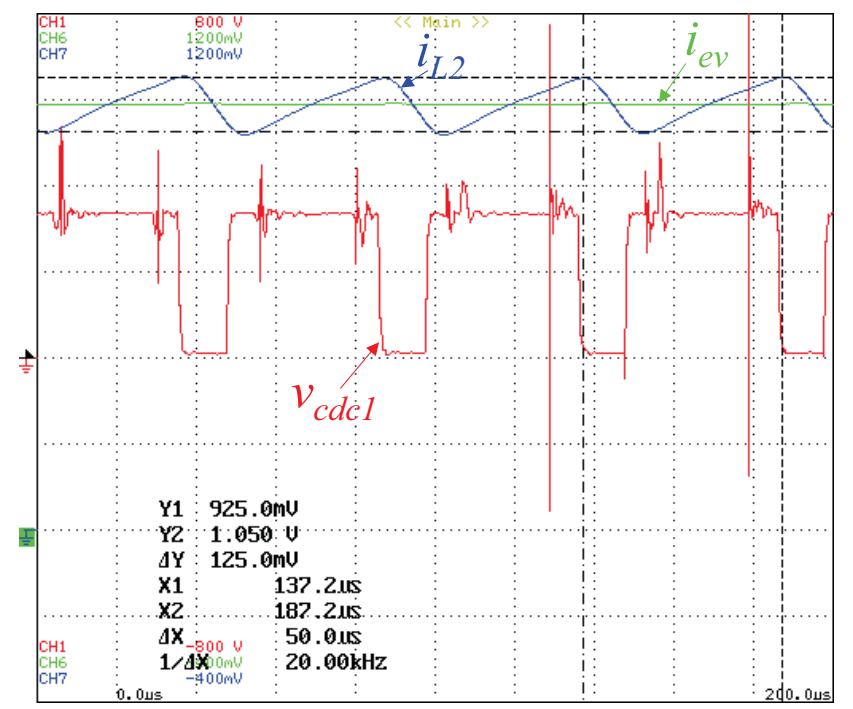

Fig. 10. Experimental results when the EV batteries are charged with energy from the power grid: Current in the inductance $L_{2}\left(i_{L 2}: 2 \mathrm{~A} / \mathrm{div}\right)$; Current in the $\mathrm{EV}$ batteries $\left(i_{e v}: 2 \mathrm{~A} / \mathrm{div}\right)$; Voltage produced by the dc-dc converter $\left(v_{c d c 1}\right.$ : $200 \mathrm{~V} /$ div).

variability of the PV power $\left(p_{p v}\right)$ is reflected in the grid power $\left(p_{g}\right)$. Also in this operation mode, the negative value of the grid power $\left(p_{g}\right)$ means that the electrical grid receives energy.

\section{R2V Operation Mode}

Fig. 13 shows the grid power $\left(p_{g}\right)$, the EV power $\left(p_{e v}\right)$, and the PV power $\left(p_{p v}\right)$ during the R2V operation mode. In this operation mode the grid power is zero and the EV power is equal to the PV power, i.e., the energy produced by the PV panels is used to charge the EV batteries. This operation mode represents an important advantage of the proposed TPIT, since the electrical grid is not used as energy intermediary between the PV panels and the EV batteries, i.e., a direct dc to dc interface is used as off-board charger, reducing the number of conversion stages in comparison with a classical topology.

\section{G2V,V2G and R2V Operation Modes}

Fig. 14 shows the grid power $\left(p_{g}\right)$, the EV power $\left(p_{e v}\right)$, and the PV power $\left(p_{p v}\right)$ during the G2V, V2G, R2V and R2G operation modes. In the first time interval (1) the EV power increases progressively, in order to avoid sudden variations (i.e., to avoid an instantaneously variation from 0 to $3 \mathrm{~kW}$ )

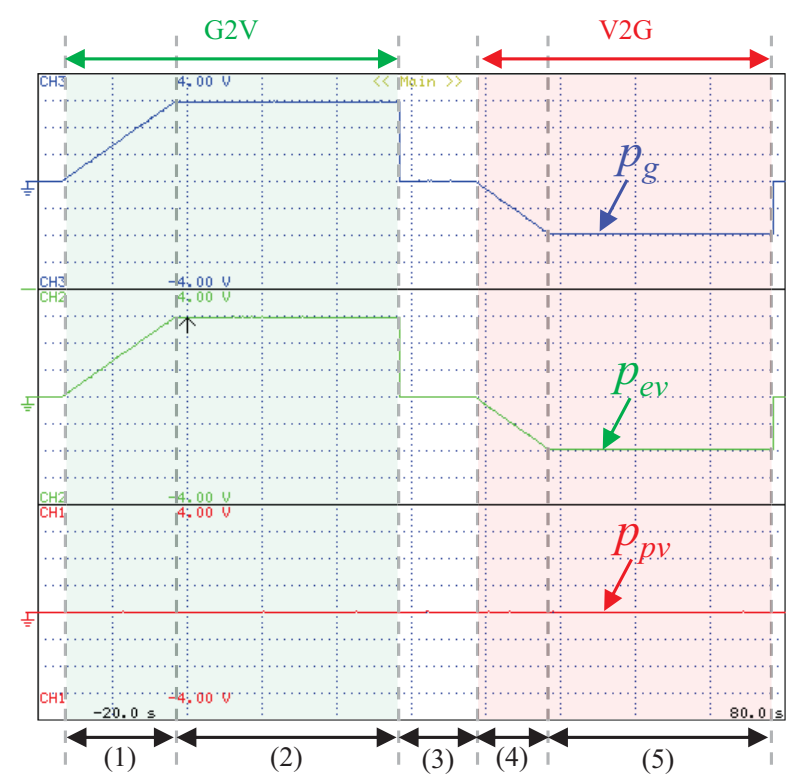

Fig. 11. Experimental results during the $\mathrm{G} 2 \mathrm{~V}$ and $\mathrm{V} 2 \mathrm{G}$ operation modes: Grid power $\left(p_{g}: 1 \mathrm{~kW} /\right.$ div); EV power ( $p_{e v}: 1 \mathrm{~kW} /$ div); PV power $\left(p_{p v}: 1 \mathrm{~kW} / \mathrm{div}\right)$.

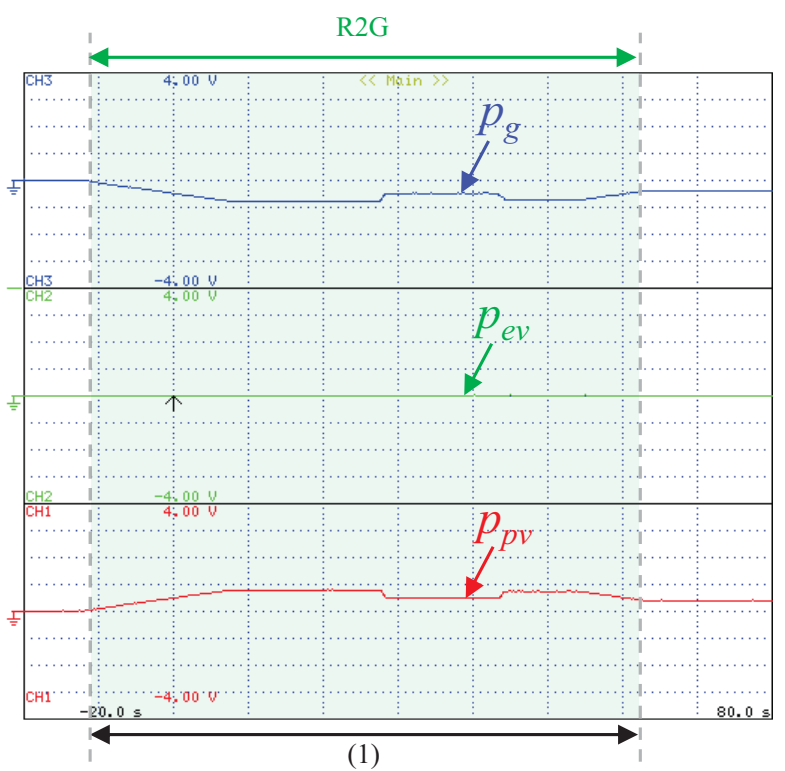

Fig. 12. Experimental results during the R2G operation mode: Grid power $\left(p_{g}: 1 \mathrm{~kW} / \mathrm{div}\right)$; EV power ( $\left.p_{e v}: 1 \mathrm{~kW} / \mathrm{div}\right)$; PV power $\left(p_{p v}: 1 \mathrm{~kW} / \mathrm{div}\right)$.

and power quality problems, until the power of $3 \mathrm{~kW}$. During this time interval the EV receives energy from the PV panels and from the electrical grid. Therefore, this time interval corresponds to the combined operation of the G2V and R2V modes. During the second time interval (2) the EV power $\left(p_{e v}\right)$ is maintained constant, representing the normal G2V operation mode. It is important to note that the EV power is constant, but the grid power changes accordingly to the power of the PV panels. In the third time interval (3), the EV charging process is interrupted and the power produced by the PV panels is injected into the power grid, which corresponds to the R2G operation mode. The negative value of the grid power $\left(p_{g}\right)$ only means that the electrical grid receives energy. It is important to note that the TPIT, according to the control algorithm, accommodates the variations of power from the PV 


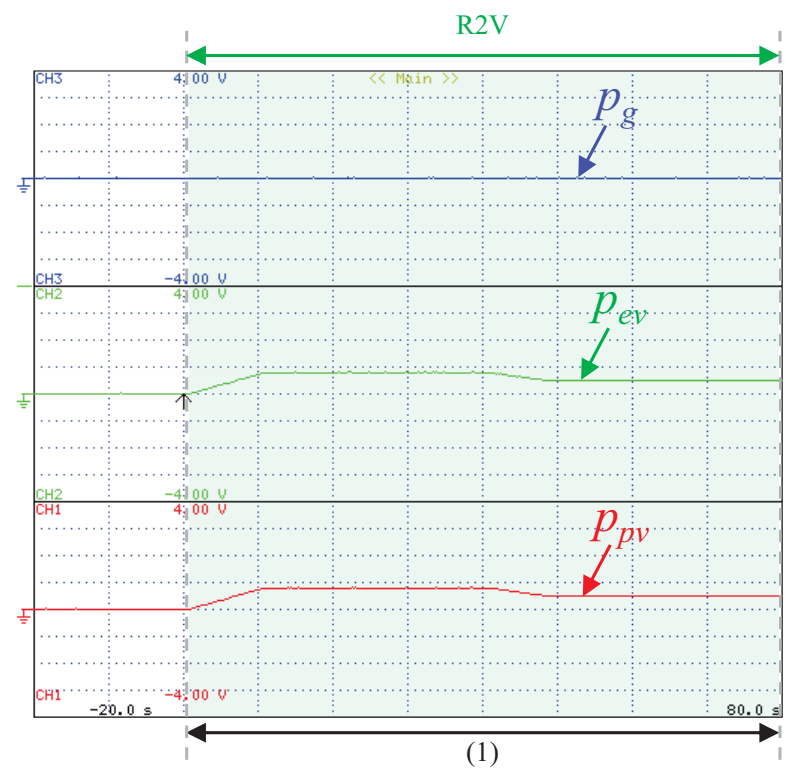

Fig. 13. Experimental results during the G2V and R2V operation modes: Grid power $\left(p_{g}: 1 \mathrm{~kW} / \mathrm{div}\right)$; EV power $\left(p_{e v}: 1 \mathrm{~kW} / \mathrm{div}\right)$; PV power $\left(p_{p v}: 1 \mathrm{~kW} / \mathrm{div}\right)$.

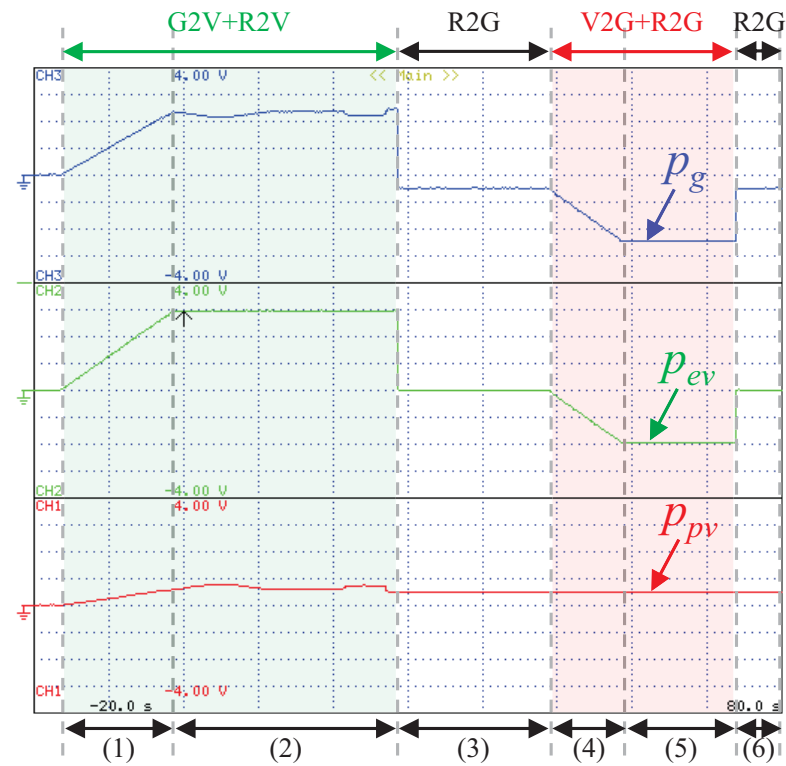

Fig. 14. Experimental results during the G2V, V2G, R2G and R2V operation modes: Grid power ( $\left.p_{g}: 1 \mathrm{~kW} / \mathrm{div}\right) ; \mathrm{EV}$ power $\left(p_{e v}: 1 \mathrm{~kW} / \mathrm{div}\right)$; $\mathrm{PV}$ power $\left(p_{p v}: 1 \mathrm{~kW} / \mathrm{div}\right)$.

panels, unless such variations jeopardize its integrity. During the fourth time interval (4) the EV power decreases progressively, in order to avoid sudden variations and prevent power quality problems, until the power of $-2 \mathrm{~kW}$. During the fifth time interval (5) this power is maintained constant, representing the normal $\mathrm{V} 2 \mathrm{G}$ operation mode. During this operation mode, the grid power is the sum of the EV power with the PV power. After this time interval, in the sixth time interval (6) the $\mathrm{V} 2 \mathrm{G}$ operation mode is interrupted and the energy from the PV panels is injected into the electrical grid (R2G operation mode).

\section{CONCLUSION}

This paper presents a three-port integrated topology (TPIT) used to interface an electric vehicle (EV) and renewables from photovoltaic (PV) panels with the electrical grid. With the proposed topology, it is possible to reduce the number of conversion stages in comparison with a classical topology, also allowing the definition of new operation modes and control algorithms, without neglecting the power quality in the electrical grid side. The proposed TPIT is experimentally validated in four main operation modes, where it is possible to deliver energy from the PV panels to the EV or to the electrical grid, and to exchange energy in bidirectional mode between the EV and the electrical grid. The paper presents in detail the proposed algorithms to control the TPIT based on the FBD power theory, the predictive current control strategies, and the developed hardware, including the power converters and the digital control system. The experimental results confirm the benefits of the proposed topology, including the operation with sinusoidal grid current and low THD in all the operating modes.

\section{ACKNOWLEDGMENT}

This work has been supported by FCT - Fundação para a Ciência e Tecnologia in the scope of the project: PEstUID/CEC/00319/2013. This work has been supported by COMPETE: POCI-01-0145-FEDER-007043 and FCT Fundação para a Ciência e Tecnologia within the Project Scope: UID/CEC/00319/2013. This work is financed by the ERDF - European Regional Development Fund through the Operational Programme for Competitiveness and Internationalisation - COMPETE 2020 Programme, and by National Funds through the Portuguese funding agency, FCT Fundação para a Ciência e a Tecnologia, within project SAICTPAC/0004/2015- POCI- 01-0145-FEDER-016434.

\section{REFERENCES}

[1] Wencong Su, Habiballah Rahimi-Eichi, Wente Zeng, Mo-Yuen Chow, "A Survey on the Electrification of Transportation in a Smart Grid Environment," IEEE Trans. Ind. Informat., vol.8, no.1, pp.1-10, Feb. 2012.

[2] C. C. Chan, Alain Bouscayrol, Keyu Chen, "Electric, Hybrid, and FuelCell Vehicles: Architectures and Modeling," IEEE Trans. Veh. Technol., vol.59, no.2, pp.589-598, Feb. 2010.

[3] C. C. Chan, "The State of the Art of Electric, Hybrid, and Fuel Cell Vehicles," Proc. IEEE, vol.95, no.4, pp.704-718, Apr. 2007.

[4] João C. Ferreira, Vítor Monteiro, José A. Afonso, João L. Afonso, "Mobile Cockpit System for Enhanced Electric Bicycle Use," IEEE Trans. Ind. Informat., vol.11, no.5, pp.1017-1027, Oct. 2015.

[5] João A. Peças Lopes, Filipe Soares, Pedro M. Rocha Almeida, "Integration of Electric Vehicles in the Electric Power Systems," Proc. IEEE, vol.99, no.1, pp.168-183, Jan. 2011.

[6] J. Carlos Gómez, Medhat M. Morcos, "Impact of EV Battery Chargers on the Power Quality of Distribution Systems," IEEE Trans. Power Del., vol.18, no.3, pp. 975-981, July 2003.

[7] Nikolaos G. Paterakis, Ozan Erdinç, Anastasios G. Bakirtzis, João P. S. Catalão, "Optimal Household Appliances Scheduling Under DayAhead Pricing and Load-Shaping Demand Response Strategies," IEEE Trans. Ind. Informat., vol.11, no.6, pp.1509-1519, Dec. 2015.

[8] Changsong Chen, Shanxu Duan, “Optimal Integration of Plug-In Hybrid Electric Vehicles in Microgrids," IEEE Trans. Ind. Informat., vol.10, no.3, pp.1917-1926, Aug. 2014.

[9] Vehbi C. Gungor, Dilan Sahin, Taskin Kocak, Salih Ergut, Concettina Buccella, Carlo Cecati, Gerhard P. Hancke, "Smart Grid and Smart 
Homes - Key Players and Pilot Projects," IEEE Ind. Electron. Mag., vol.6, pp.18-34, Dec. 2012.

[10] Chenrui Jin, Jian Tang, Prasanta Ghosh, "Optimizing Electric Vehicle Charging: A Customer's Perspective," IEEE Trans. Veh. Technol., vol.62, no.7, pp.2919-2927, Sept. 2013.

[11] Ming Zeng, Supeng Leng, Yan Zhang, "Power Charging and Discharging Scheduling for V2G Networks in the Smart Grid," IEEE ICC International Conference on Communications Workshops, pp.1052-1056, June 2013

[12] Mithat C. Kisacikoglu, Metin Kesler, Leon M. Tolbert, "Single-Phase On-Board Bidirectional PEV Charger for V2G Reactive Power Operation," IEEE Trans. Smart Grid, vol.6, no.2, pp.767-775, Mar. 2015.

[13] Rong Yu, Weifeng Zhong, Shengli Xie, Chau Yuen, Stein Gjessing, Yan Zhang, "Balancing Power Demand Through EV Mobility in Vehicle-to-Grid Mobile Energy Networks," IEEE Trans. Ind. Informat., vol.12, no.1, pp.79-90, Feb. 2016.

[14] Fabian Kennel, Daniel Görges, Steven Liu, "Energy Management for Smart Grids With Electric Vehicles Based on Hierarchical MPC," IEEE Trans. Ind. Informat., vol.9, no.3, pp.1528-1537, Aug. 2013.

[15] Rong Yu, Weifeng Zhong, Shengli Xie, Chau Yuen, Stein Gjessing, Yan Zhang, "Balancing Power Demand through EV Mobility in Vehicle-to-Grid Mobile Energy Networks," IEEE Trans. Ind. Informat., vol.12, no.1, pp.79-90, Feb. 2016

[16] Murat Yilmaz, Philip T. Krein, "Review of the Impact of Vehicle-toGrid Technologies on Distribution Systems and Utility Interfaces," IEEE Trans. Power Electron., vol.28, no.12, pp.5673-5689, Dec. 2013.

[17] Chunhua Liu, K. T. Chau, Diyun Wu, Shuang Gao, "Opportunities and Challenges of Vehicle-to-Home, Vehicle-to-Vehicle, and Vehicle-toGrid Technologies," Proc. IEEE, vol.101, no.11, pp.2409-2427, Nov. 2013.

[18] Vítor Monteiro, J. G. Pinto, João L. Afonso, "Operation Modes for the Electric Vehicle in Smart Grids and Smart Homes: Present and Proposed Modes," IEEE Trans. Veh. Tech., vol.65, no.3, pp.10071020, Mar. 2016

[19] Sam Weckx, Johan Driesen, "Load Balancing With EV Chargers and PV Inverters in Unbalanced Distribution Grids," IEEE Trans. Sustain. Energy, vol.6, no.2, pp.635-643, Apr. 2015.

[20] Willett Kempton, Jasna Tomic, "Vehicle-to-Grid Power Implementation: From Stabilizing the Grid to Supporting Large-Scale Renewable Energy," ELSEVIER Journal of Power Sources, vol.144, pp.280-294, Apr. 2015.

[21] Shuang Gao, K. T. Chau, Chunhua Liu, Diyun Wu, C. C. Chan, "Integrated Energy Management of Plug-in Electric Vehicles in Power Grid With Renewables," IEEE Trans. Veh. Technol., vol.63, no.7, pp.3019-3027, Sept. 2014.

[22] Jun Hua Zhao, Fushuan Wen, Zhao Yang Dong, Yusheng Xue, Kit Po Wong, "Optimal Dispatch of Electric Vehicles and Wind Power Using Enhanced Particle Swarm Optimization," IEEE Trans. Ind. Informat., vol.8, no.4, pp.889-899, Nov. 2012

[23] J. A. Peças Lopes, F. J. Soares, P. M. Almeida, M. Moreira da Silva, "Smart Charging Strategies for Electric Vehicles: Enhancing Grid Performance and Maximizing the Use of Variable Renewable Energy Resources," EVS24 International Battery, Hybrid and Fuel Cell Electric Vehicle Symposium, pp.1-11, May 2009.

[24] Peerapat Vithayasrichareon, Graham Mills, Iain F. MacGill, "Impact of Electric Vehicles and Solar PV on Future Generation Portfolio Investment," IEEE Trans. Sustain. Energy, vol.6, no.3, pp.899-908, July. 2015

[25] Wayes Tushar, Chau Yuen, Shisheng Huang, David B. Smith, H. Vincent Poor, "Cost Minimization of Charging Stations With Photovoltaics: An Approach with EV Classification," IEEE Trans. Intell. Transp. Syst., vol.17, no.1, pp.156-169, Jan. 2016.

[26] Mosaddek Hossain Kamal Tushar, AdelW. Zeineddine, Chadi Assi, "Demand-Side Management by Regulating Charging and Discharging of the EV, ESS, and Utilizing Renewable Energy," IEEE Trans. Ind. Informat., vol.14, no.1, pp.117-126, Jan. 2018.

[27] Kalpesh Chaudhari, Abhisek Ukil, K Nandha Kumar, Ujjal Manandhar, Sathish Kumar Kollimalla, "Hybrid Optimization for Economic
Deployment of ESS in PV-Integrated EV Charging Stations," IEEE Trans. Ind. Informat., vol.14, no.1, pp.106-116, Jan. 2018.

[28] Xinyi Lu, Nian Liu, Qifang Chen, Jianhua Zhang, "Multi-objective Optimal Scheduling of a DC Micro-grid Consisted of PV System and EV Charging Station," IEEE ISGT Innovative Smart Grid Technologies, pp.487-491, May 2014.

[29] Joshua Traube, Fenglog Lu, Dragan Maksimovic, "Photovoltaic Power System with Integrated Electric Vehicle DC Charger and Enhanced Grid Support," EPE/PEMC International Power Electronics and Motion Control Conference, pp.1-5, Sept. 2012.

[30] Taesik Park, Taehyung Kim, "Novel Energy Conversion System Based on a Multimode Single-Leg Power Converter," IEEE Trans. Power Electron., vol.28, no.1, pp.213-220, Jan. 2013.

[31] Gustavo Gamboa, Christopher Hamilton, Ross Kerley, Sean Elmes, Andres Arias, John Shen, Issa Batarseh, "Control Strategy of a MultiPort, Grid Connected, Direct-DC PV Charging Station for Plug-in Electric Vehicles," IEEE Energy Conversion Congress and Exposition, pp.1173-1177, Sept. 2010.

[32] Preetham Goli, Wajiha Shireen, "PV Integrated Smart Charging of PHEVs Based on DC Link Voltage Sensing," IEEE Trans. Smart Grid, vol.5, no.3, pp.1421-1428, May 2014.

[33] Christopher Hamilton, Gustavo Gamboa, John Elmes, Ross Kerley, Andres Arias, Michael Pepper, John Shen, Issa Batarseh, "System Architecture of a Modular Direct-DC PV Charging Station for Plug-in Electric Vehicles," IEEE IECON Annual Conference on Industrial Electronics Society, pp.2516-2520, Nov. 2010.

[34] Vítor Monteiro, J. G. Pinto, Bruno Exposto, Delfim Pedrosa, João L. Afonso, "Multifunctional Converter to Interface Renewable Energy Sources and Electric Vehicles with the Power Grid in Smart Grids Context," ICEE International Conference on Energy and Environment: Bringing Together Engineering and Economics, Guimarães Portugal, pp.654-661, June 2015.

[35] Andrés A. Valdez-Fernández, Pánfilo R. Martínez-Rodríguez, Gerardo Escobar, Cesar A. Limones-Pozos, José M. Sosa, "A Model-Based Controller for the Cascade H-Bridge Multilevel Converter Used as a Shunt Active Filter," IEEE Trans. Ind. Electron., vol.60, no.11, pp.5019-5028, Nov. 2013.

[36] M. Depenbrock, "The FBD-Method, a Generally Applicable Tool for Analyzing Power Relations," IEEE Trans. Power Syst., vol.8, no.2, pp.381-387, May 1993.

[37] M. Karimi-Ghartemani, M. R. Iravani, "A Nonlinear Adaptive Filter for Online Signal Analysis in Power Systems: Applications," IEEE Trans. Power Del., vol.17, no.2, pp.617-622, Apr. 2002.

[38] Moacyr Aureliano Gomes de Brito, Luigi Galotto, Jr., Leonardo Poltronieri Sampaio, Guilherme de Azevedo e Melo, Carlos Alberto Canesin, "Evaluation of the Main MPPT Techniques for Photovoltaic Applications," IEEE Trans. Ind. Electron., vol.60, no.3, pp.1156-1167, Mar. 2013.

[39] Delfim Pedrosa, Vítor Monteiro, Henrique Gonçalves, Júlio S. Martins, João L. Afonso, "A Case Study on the Conversion of an Internal Combustion Engine Vehicle into an Electric Vehicle," IEEE VPPC Vehicle Power and Propulsion Conference, pp.1-5, Oct. 2014.

[40] Vítor Monteiro, J. G. Pinto, João L. Afonso, "Operation Modes for the Electric Vehicle in Smart Grids and Smart Homes: Present and Proposed Modes," IEEE Trans. Veh. Tech., vol.65, no.3, pp.10071020, Mar. 2016.

[41] Vítor Monteiro, João C. Ferreira, Andrés A. Nogueiras Meléndez, João L. Afonso, "Model Predictive Control Applied to an Improved FiveLevel Bidirectional Converter," IEEE Trans. Ind. Electron., vol.63, no.9, pp.5879-5890, Sept. 2016. 


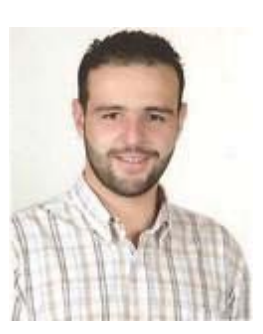

Vítor Monteiro (S'10) was born in Guimarães, Portugal, on May 1984. He received the M.Sc. and the Ph.D. in Industrial Electronics and Computers Engineering, from the School of Engineering of the University of Minho, in 2012 and 2016, respectively. Since 2008 he is a member of the Group of Energy and Power Electronics (GEPE) of the Centro Algoritmi, at the University of Minho. His research interests are related with Power Electronics Converters, Digital Control Techniques, Smart Grids, and Electric Vehicles. Vítor is a student member of IEEE, member of the Industrial Electronics Society, and member of the Vehicular Technology Society.

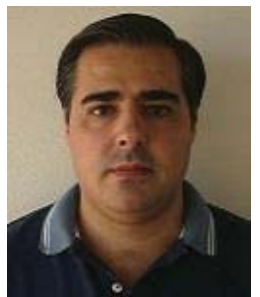

J. G. Pinto (M'16) was born in Guimarães, Portugal, in 1977. He is Assistant Professor at the Department of Industrial Electronics of the University of Minho, Portugal, where he works since 2013. He received the degree in Electronics Engineering and the M.Sc. degree in Industrial Electronics from the University of Minho, Portugal, in 2001 and 2004, respectively. From 2002 to 2006 worked as invited Assistant Lecturer at the Electrical Department of the Polytechnic Institute of Bragança, Portugal. From 2006 to 2012 he worked as a researcher at the Group of Energy and Power Electronics (GEPE) of the Centro Algoritmi, at the University of Minho. $\mathrm{He}$ received the $\mathrm{PhD}$ degree in Electronics and Computer Engineering from the University of Minho, in 2012. His research interests are related with Power Electronics, Power Quality and Digital Control of Power Converters.

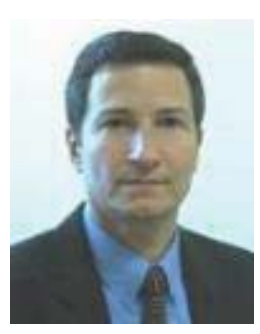

João Luiz Afonso (M'00) was born in Rio de Janeiro, Brazil, in 1963. He received the B.S. and M.Sc. degrees in Electrical Engineering from the Federal University of Rio de Janeiro in 1986 and 1991, respectively, and the Ph.D. degree in Industrial Electronics from the University of Minho, Guimarães, Portugal, in 2000. Since 1993, he has been with the Department of Industrial Electronics, University of Minho, where he is Associate Professor with Habilitation. He teaches Electrical Machines, Complements of Power Electronics, Electrical Power Quality, Active Power Filters and Renewable Energy. He is a researcher with the Group of Energy and Power Electronics (GEPE), and he coordinates the thematic strand of Sustainable and Smart Cities of the Centro Algoritmi. His research interests include: Power Quality,
Active Power Filters, Renewable Energy, Electric Vehicles, Energy Efficiency, Energy Storage Systems, Innovative Railway Systems, Smart Grids and Smart Cities. 